\title{
Intralaminar Fracture Toughness Characterization of Composite Laminates
}

\author{
Maurício V. Donadon and Sérgio Frascino Muller de Almeida \\ Instituto Tecnológico de Aeronautica-ITA \\ Brazil
}

\section{Introduction}

The current emphasis within the composite design community is gradually shifting from achieving minimum weight designs at all costs to more cost-effective and damage tolerant structural designs. A damage tolerant structure must not only be able to effectively absorb energy locally at the point of damage initiation but must also be fail-safe. A very efficient way of designing a composite fail-safe structure is to provide it with the ability to arrest a potentially catastrophic crack by increasing its fracture resistance. The fracture behaviour of composites can be quantified by measuring its toughness and it can be broadly classified into interlaminar and intralaminar fractures. Most of the work reported in the recent literature has focused on the investigation of the interlaminar behaviour of composites with a limited number of works addressing the intralaminar fracture behaviour.

The measurement of intralaminar toughness requires a pre-cracked specimen and in most cases, particularly for CFRP materials. Its determination can be based on the Linear Elastic Fracture Mechanics (LEFM) approach. Different types of specimens and crack geometries are currently available in the literature to characterise the intralaminar fracture behaviour of composites under pure mode I (Cowley \& Beaumont, 1997; Konstantinos et al., 2005), mode II and mixed-mode loading (Lin \& Shetty, 2003), however none of them are standardised. The specimen selection depends on the material system under investigation and expected toughness values range from initiation to propagation. It is also worth mentioning that most of these specimens were originally designed for fracture in isotropic materials. The poor performance of composites in shear and compression loading, compared to tension loading in the fibre direction may lead to failure prior to crack growth. Such restrictions impose limitations on their applicability and alternative specimen designs are needed. For mode-I, the Overheight Compact Tension (OCT) specimen has the advantage of promoting a stable crack growth which eventually enables the evaluation of both initiation and propagation values for the intralaminar toughness.

Jose et al. (2001) investigated the mode I intralaminar toughness of carbon/ epoxy cross-ply laminates using overheight compact tension specimens. The experimental results were compared with finite element simulations using a modified crack-closure integral method and a methodology for calculating the stress intensity factor associated with matrix cracking and fibre fracture was presented. Based on the work by Jose et al. (2001), Pinho et al. (2006a) investigated the intralaminar toughness associated with fibre breakage in tension and fibre kinking in compression in unidirectional pre-preg composites using Compact Tension (CT) 
and Compact Compression (CC) specimens. A very consistent resistance curve (R-Curve) containing initiation and propagation values was obtained in tension, with a marked increase in the toughness values in compression due to fibre compression kinking. The authors attribute the increase in the toughness in compression to the contact in the crushed area. In fact, the contact is a problem even in tension, if the specimen is subjected to cyclic loading-unloading, due to debris effects which prevent the total crack closure, resulting in permanent displacements (Konstantinos et al., 2005). Kostopulos and co-workers (1998) proposed a modified compliance method to handle problems in which permanent displacements are an important issue. The method is based on the Non-Linear Fracture Mechanics (NLFM) approach and the resultant nonlinear fracture toughness is composed of elastic and non-elastic terms due to the presence of irreversible deformations. The method uses an effective crack length based on a semi-empirical equation.

The increasing computational resources combined with recent developments on advanced physically based failure models have allowed reliable prediction of progressive damage in composites by using the finite element method (Iannucci e al., 2006; Pinho et al., 2006b; Donadon et al., 2009). These models require, among others parameters, a number of intralaminar fracture energies as input parameters. For instance, for pure tensile failure in both transverse and longitudinal directions the fracture energy can be determined using the Overheight Compact Tension (OCT) specimen. In a similar way the Compact Compression (CC) specimen can be used to determine the fracture energy associated with fibre kinking (Pinho et al., 2006). The fracture energy associated with shear dominated failure modes can be measured using the Four Point End Notched Flexure (4ENF) specimens (Martin et al., 1998).

This chapter intends to present a detailed discussion on test methods and data reduction schemes for mode-I intralaminar fracture toughness characterization of composite laminates. Additionally, fracture mechanics based finite element models of all described tests were developed to confirm the experimental results. Details on specimen manufacturing and preparation for different pre-cracked geometries including Overheight Compact Tension (OCT), double edge notch (DEN) and centrally cracked four-pointbending (4PBT) test specimens are also presented and discussed. The limitations of the applicability of the standard data reduction schemes for the determination of intralaminar toughness of composite materials are also addressed in this chapter. A methodology based on the numerical evaluation of the strain energy release rate using the Jintegral method is presented in details. This methodology was used to derive new geometric correction functions for the determination of the stress intensity factor for composites. The proposed method accounts for material anisotropy and finite specimen dimension effects regardless of the geometry. The approach has been validated for alternative non-standard specimen geometries. The chapter ends by showing a comparison between experimental results obtained using different data reduction schemes. A discussion on advantages, disadvantages and limitations of each method is also presented.

\section{Specimen configurations and data reduction schemes}

Strictly speaking, no data reduction scheme for the computation of the mode-I, mode II and mixed-mode loading intralaminar toughness as well as test standards are currently available in the literature for composite materials. Most researchers employ the same data reduction schemes and test standards as the one used for isotropic materials; however, their 
applicability for composites and the reliability of the results are questionable. The standard data reduction schemes for isotropic materials are presented herein and it will be shown that in their original forms these expressions are not applicable for the material system investigated in this chapter.

\subsection{Overheight Compact Tension (OCT)}

The determination of the stress intensity factor for isotropic materials using OCT specimens is based on the ASTM E399-90 standard (Annual book of ASTM standards, 1993),

$$
K_{I C}=\frac{P}{h \sqrt{w}} f(a / w)
$$

where $P$ is the applied load, $h$ is the thickness and $w$ is the distance from the loading line up to the crack tip, as shown in Fig. 1. $f(a / w)$ is the geometric function introduced to account for finite specimen dimension corrections, which is given by(Annual book of ASTM standards, 1993),

$$
f(a / w)=\frac{2+a / w}{(1-a / w)^{1.5}}\left[0.886+4.64(a / w)-13.32(a / w)^{2}+14.72(a / w)^{3}-5.6(a / w)^{4}\right]
$$

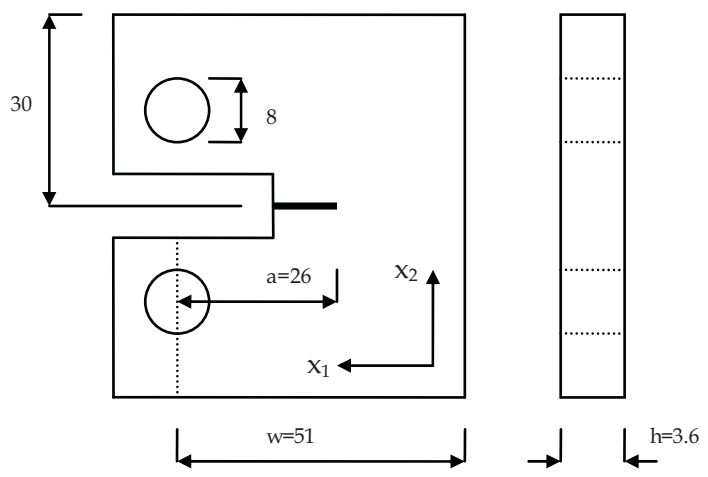

Fig. 1. Typical dimensions for the Overheight Compact Tension (OCT) specimen (dimensions in $\mathrm{mm}$ )

\subsection{Double Edge Notch (DEN)}

For the double edge notch (DEN) specimens the stress intensity factor is given by (Brown \& Strawley, 1967),

$$
K_{I C}=f(a / w) \sigma \sqrt{a}
$$

where $\sigma$ is the applied stress, $w$ is the specimen width and $a$ is the crack length, as depicted in Fig. 2. $f(a / w)$ is the finite dimension correction function given by (Brown \& Strawley, 1967),

$$
f(a / w)=1.98+0.36(2 a / w)-2.12(2 a / w)^{2}+3.42(2 a / w)^{3}
$$




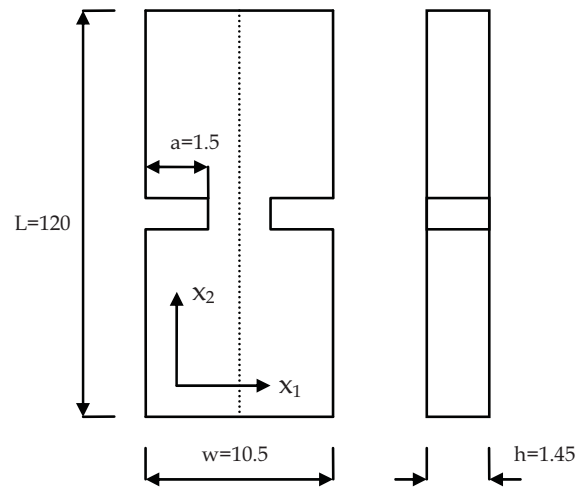

Fig. 2. Typical dimensions for the Double Edge Notch (DEN) specimen (dimensions in $\mathrm{mm}$ )

\subsection{Four Point Bending (4PBT)}

For the four point bending (4PBT) specimens the stress intensity factor is defined as (Rooke \& Cartwright, 1976),

$$
K_{I C}=\frac{6 P c \sqrt{\pi a}}{2 w h^{2}} f(a / h)
$$

where $P$ is the total applied load, $c$ is the distance between the edge of the specimen and the upper loading point (see Fig.3), $w$ and $h$ are the width and thickness of the specimen, respectively, and $f(a / h)$ is the geometric correction function given by (Rooke \& Cartw right, 1976),

$$
f(a / h)=1.12-1.39(a / w)+7.32(a / w)^{2}-13.1(a / w)^{3}+14.0(a / w)^{4}
$$

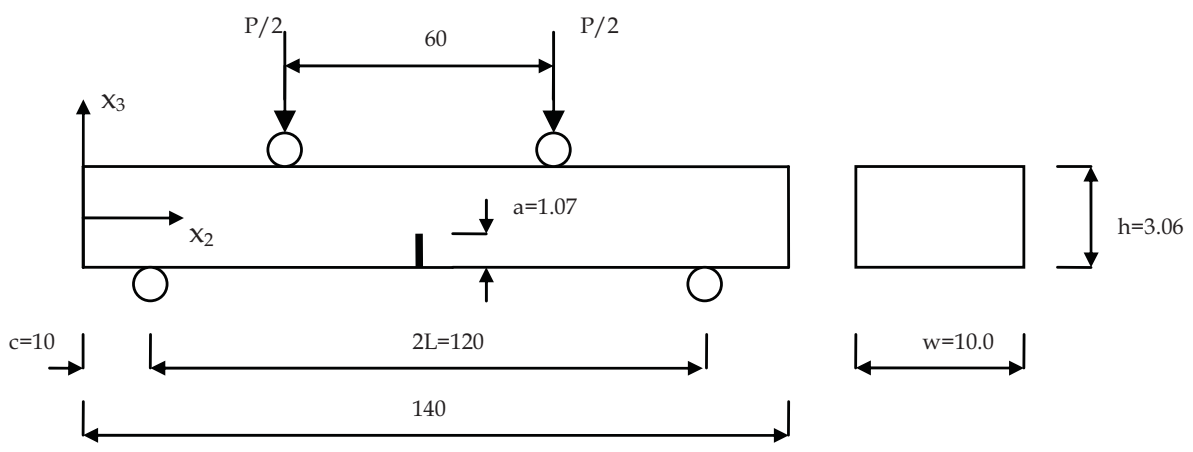

Fig. 3. Typical dimensions for the Four Point Bending (4PBT) specimen (dimensions in $\mathrm{mm}$ )

\subsection{Intralaminar fracture toughness for composites}

For an on-axis, plane stress, orthotropic plate with an initial crack subjected to in-plane loading, the fracture toughness values can be obtained from the Griffith's strain energy release rate functions as follow (Paris \& Sih, 1960; Lin et al., 1997) 


$$
G_{I c}=\frac{K_{I C}^{2}}{\sqrt{2 \bar{E}_{1} \bar{E}_{2}}} \sqrt{\alpha+\beta}
$$

with $\alpha=\sqrt{\bar{E}_{1} / \bar{E}_{2}}$ and $\beta=\bar{E}_{1} / 2 \bar{G}_{12}-\bar{v}_{12}$, where $\bar{E}_{1}, \bar{E}_{2}$ are the effective Young's modulus in the longitudinal and transverse direction, respectively, and $\bar{v}_{12}$ is the effective in-plane Poisson's ratio. $\bar{G}_{12}$ is the effective in-plane shear modulus. Equation 7 is valid for the OCT and DEN specimens. For the four point bending specimens the values of $G_{I c}$ associated with the fracture in the transverse direction can be determined as (Rooke \& Cartwright, 1976),

$$
G_{I c}=\frac{K_{I C}^{2}}{\bar{E}_{2}}
$$

where $\bar{E}_{2}=E_{2}$ under plane stress and $\bar{E}_{2}=E_{2} /\left(1-v_{12}^{2}\right)$ under plain strain conditions.

\section{Stress intensity factor for orthotropic materials}

Experimental and numerical studies carried out by Donadon et al. (2007) have shown that the stress intensity factor for composites is significantly overestimated by the direct application of Eqs. (1), (3) and (5). The authors suggest that a possible source of error is the finite geometry correction factor, which was originally derived for isotropic materials. In order to tackle this problem, the authors proposed a methodology based on the numerical evaluation of the Jintegral to derive new finite geometry correction functions for composite specimens. A detailed description on the methodology proposed by the authors is given in the following sections.

\subsection{Theoretical aspects}

The numerical evaluation of the strain energy release rate associated with intralaminar fracture was based on the Jintegral method. For this purpose, ABAQUS Standard version 6.5 was used (ABAQUS, 2005). The software provides a calculation procedure for Jintegral based on the virtual crack extension/domain integral methods (ABAQUS, 2005). Alternatively, the $J$-integral can be numerically evaluated by measuring the change in strain energy, $\Delta U$ of the specimen with a crack advance, $\Delta a$, where the $J$-integral is given as the negative differential of strain energy with respect to crack length that is,

$$
J=-\frac{\partial U}{\partial A} \approx \frac{U(a)-U(a+\Delta a)}{h \Delta a}
$$

where $U(a)$ and $U(a+\Delta a)$ are the strain energies associated with a crack length $a$ and $a+\Delta a$, respectively. $\Delta a$ is the crack increment and $h$ is the thickness of the specimen. Although both methods provide the same results in the linear elastic regime, the latter requires extra data post-processing whilst in the former the $J$-integral values are obtained straightway. For a linear elastic orthotropic material under plane-stress assumption loaded in mode-I opening, $J=G_{I c}$ and the stress intensity factor can be related to the Jintegral values using (Lin et al., 1997), 


$$
K_{I C}^{2}=\frac{J \sqrt{\bar{E}_{1} \bar{E}_{2}}}{\sqrt{(\alpha+\beta) / 2}}
$$

where $\alpha$ and $\beta$ are orthotropic constants previously defined in Eq. (7). Eq. (10) is valid for OCT and DEN specimens. For the 4PBT specimens, the relationship between the stress intensity factor and Jintegral values is obtained from Eq. (8) with $J=G_{I c}$,

$$
K_{I C}^{2}=\bar{E}_{2} J
$$

By using Eqs. (1), (3), (5), (10) and (11), a new correction function which incorporates orthotropic effects may be obtained using the following procedure:

1. For the OCT and DEN specimens, compute Jintegral values for different crack lengths and for each J-integral value $\left(J_{i}\left(a_{i}\right)\right)$, compute the stress intensity factor using Eq. (10),

$$
K_{I c}^{i}=\frac{\rho_{i}^{\ominus .5}\left(\bar{E}_{1} \bar{E}_{2}\right)^{0.25}}{(\alpha / 2+\beta / 2)^{0.25}}
$$

For the 4PBT specimen, compute Jintegral values for different crack lengths and for each Jintegral value $\left(J_{i}\left(a_{i}\right)\right)$, compute the stress intensity factor using Eq. (11),

$$
K_{I c}^{i}=\sqrt{\overline{E_{2}} J_{i}}
$$

2. From Eqs. (1), (3) and (5) compute a new correction function $F\left(a_{i}\right)$. The new correction functions for OCT, DEN and 4PBT specimens are respectively given by,

$$
\begin{aligned}
& F\left(a_{i}\right)=\frac{K_{I c}^{i} h \sqrt{w}}{P_{i}} \quad(\mathrm{OCT}) \\
& F_{i}\left(a_{i}\right)=\frac{K_{I C}}{\sigma \sqrt{a}} \quad(\mathrm{DEN}) \\
& F\left(a_{i}\right)=\frac{K_{I C} w h^{2}}{3 P c \sqrt{\pi a_{i}}} \quad(4 \mathrm{PBT})
\end{aligned}
$$

3. The $F(a)$ values are plotted against their correspondent crack lengths and the new correction function is obtained by finding the best fit function which interpolates those points.

\section{Materials and laminates manufacturing}

The fabric used in the experimental part of this chapter consists of a hybrid plain weave fabric supplied by EUROCARBON ${ }^{\circledR}$ and PRIME 20LV® two part epoxy resin system, supplied by GURIT. The fabric is composed of T700-12K-50C carbon fibres in the warp direction and PPG EC09 34*2 S150 1383 glass fibres in the weft direction. The fabric configuration, material local axes and intralaminar cracking directions are illustrated in Fig. 4. 


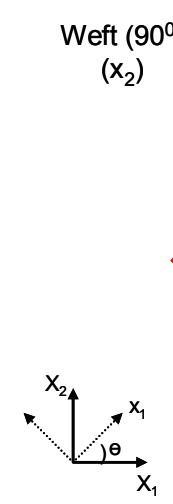

(a)

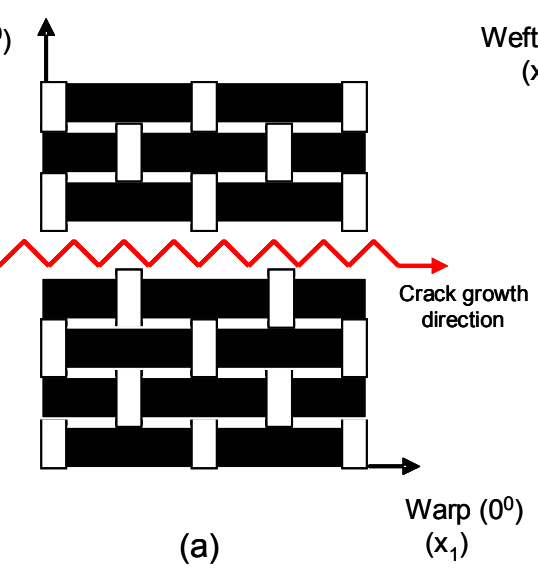

$\left(x_{1}\right)$

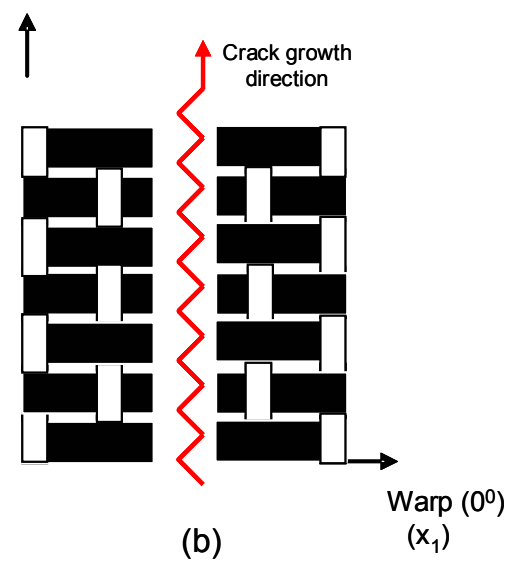

(b)

Fig. 4. Hybrid plain weave fabric: (a) Longitudinal crack grow th direction, (b) Transverse crack grow th direction

All laminates were manufactured using the Resin Infusion under Flexible Tooling (RIFT) process setup outlined in Fig. 5.

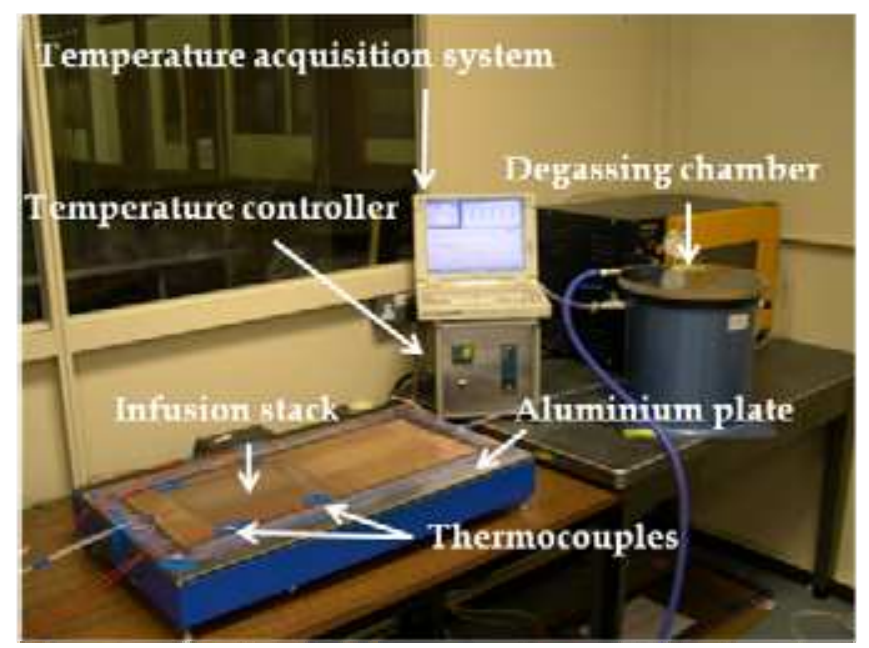

Fig. 5. Rift setup (Donadon, 2004a)

A flat $700 \mathrm{~mm} \times 400 \mathrm{~mm} \times 4 \mathrm{~mm}$ aluminium plate was used as a mould tool. Prior to laying up the fabric, the aluminium plate was covered with a melanex film and one peel ply layer, which aids the removal of the composite plates after cure. The fabrics were covered with a flow distribution medium on the upper and lower surfaces, in order to ensure complete fabric wetting-out. The resin flow medium was intentionally cut $30 \mathrm{~mm}$ shorter from the end of the preform near the vacuum vent to reduce the resin flow rate within the infusion stack. Subsequently, the infusion stack was bagged and placed on the hot platen. Next, vacuum drop tests were carried out by applying full vacuum into the infusion stack and 
monitoring the pressure using a dial gauge connected to the degassing chamber for 30 minutes. This procedure ensures the vacuum integrity within the RIFT system. Vacuum integrity is possibly the most important manufacturing parameter for the RIFT process. Infusions were carried out at room temperature $\left(25^{\circ} \mathrm{C}\right)$, with panels cured for 7 hours at 65 ${ }^{\circ} \mathrm{C}$. The temperature variation of the laminate during the curing stage was measured by attaching thermocouples on the upper surface of the stack. The temperature measurements were taken from five different positions, four of them were placed in each corner of the square plate, whereas the fifth was in the centre of the plate. The temperatures were recorded by means of a temperature data-logger connected to acquisition software. The point-to-point temperature variation was within $+/-5^{\circ} \mathrm{C}$. In order to assess the final quality of the laminates, the panels were inspected by ultrasound generating C-scans. The fibre volume fraction and void content were measured using the acid digestion method. According to c-scan images the laminates were free of any major defect, with a typical value of $53 \%$ and $1 \%$ for the fibre volume fraction and void content, respectively.

The laminate mechanical properties were measured using standard test methods (Donadon, 2004b) and are summarised in Table 1.

\begin{tabular}{ll}
\hline Stiffnesses and strengths & \\
\hline Young's modulus in the warp direction, $\mathrm{E}_{11}$ & $100 \mathrm{GPa}$ \\
Young's modulus in the weft direction, $\mathrm{E}_{22}$ & $8.11 \mathrm{GPa}$ \\
In-plane shear modulus, $\mathrm{G}_{12}$ & $3.88 \mathrm{GPa}$ \\
Major in-plane Poisson's ratio, $v_{12}$ & 0.35 \\
Tensile strength in the warp direction, $\sigma_{f, 1}^{t}$ & $2005 \mathrm{MPa}$ \\
Tensile strength in the weft direction, $\sigma_{f, 2}^{t}$ & $63 \mathrm{MPa}$ \\
Compressive strength in the warp direction, $\sigma_{f, 1}^{c}$ & $750 \mathrm{MPa}$ \\
Compressive strength in the weft direction, $\sigma_{f, 2}^{c}$ & $170 \mathrm{MPa}$ \\
In-plane shear strength, $\sigma_{12}^{f}$ & $60 \mathrm{MPa}$ \\
Mode II interlaminar fracture toughness $G_{I_{c}}$ & $2.2 \mathrm{~kJ} \mathrm{~m}^{2}$ \\
\hline
\end{tabular}

Table 1. Laminates mechanical properties

\subsection{Crack tip preparation}

A three step procedure was used to produce a sharp crack tip in the OCT specimens. Firstly a $30 \mathrm{~mm}$ length notch was inserted in the specimens using a $3.5 \mathrm{~mm}$ thick dry diamond saw. Secondly a series of razor saws were used to further increase the crack length by $10 \mathrm{~mm}$; each razor saw employed had progressively increasing number of teeth in the blade, three types were used with each removing $3.3 \mathrm{~mm}$ of material. The thickness of the razor saw blade was no more than $0.2 \mathrm{~mm}$. Lastly to produce an extreme sharp crack tip a $0.06 \mathrm{~mm}$ thick razor blade was used lightly to improve the sharpness of the crack tip. A typical micrograph illustrating the quality of the crack tip is shown in Fig. 6. 


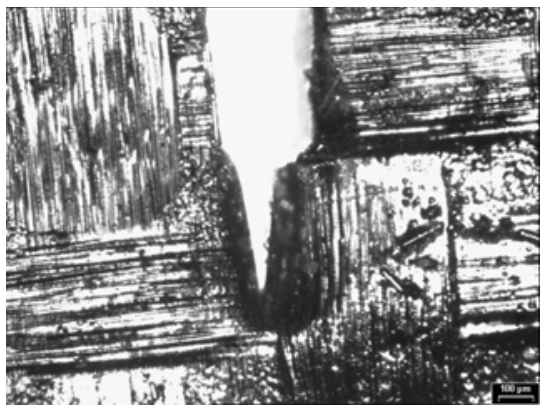

(a) $50 \mathrm{x}$

Fig. 6. Crack tip images of the OCT specimens

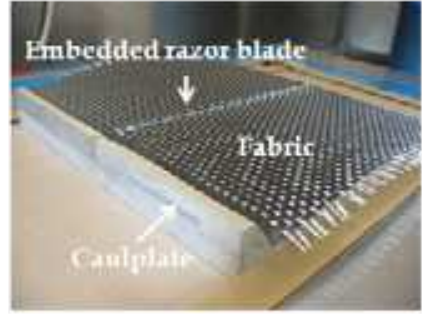

(a)

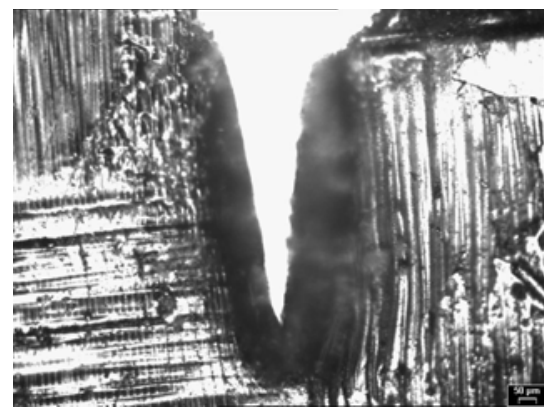

(b) $100 \mathrm{x}$

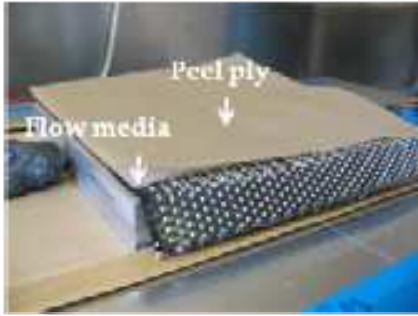

(b)

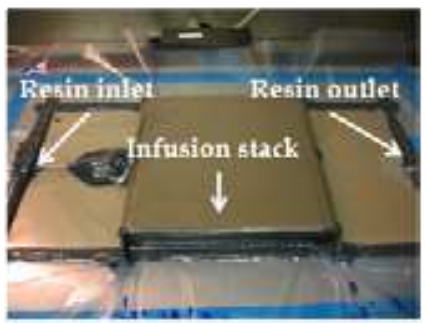

(c)

Fig. 7. Manufacturing steps for the 4PBT specimens

For the DEN specimens only the razor saws were used to insert two symmetrical $1.5 \mathrm{~mm}$ long notches in the middle of the specimens. In order to produce a pre-cracked four-pointbending specimen, the original RIFT setup had to be modified. A caulplate with a $0.06 \mathrm{~mm}$ thick sharp razor blade embedded in the mid-plane was used as a tool to introduce the precrack. The two halves of the caulplate were covered with two strips of peel ply to aid the removal of the composite panel after cure. The blade had a protruding height of $1.07 \mathrm{~mm}$ so three plies on each side of the blade had to be used so the crack tip was flush with the top surface of the stacked plies. The plies were cut in two halves along the warp direction (parallel to the carbon fibres) and the two halves were laid up on the top of the peel ply strips. The next step to produce the pre-cracked laminate was to stack more plies on the 
bottom three plies. Since the blade tip was now flush with the bottom plies, any plies that were stacked did not require to be cut in half. Hence, seven additional plies were placed on top of the crack resulting in the fibre stack being ten-ply thick. The fabric was then covered with another continuous peel ply layer followed by the flow media and another peel-ply layer on top of the stack. Flow medium was not applied below the fibre stack due to the stack being thin and overall dimensions being small. Moreover, the use of a bottom flow media would have increased the overall rate of infusion to the extent that through thickness infusion of the stack would have been limited thus promoting the presence of voids. The inlet for resin transfer had to be raised to the same level as the fibre stack to maximise fibre wet-out. Any blunt and malleable platform can be employed for this purpose. In this study a ball of tack tape was used as it had the added advantage of securing a relatively large proportion of the inlet pipe. Subsequently, the infusion arrangement was bagged and vacuum tested, infusion and cure were carried out. The specimen manufacturing steps are shown in Figs. 7 (a), 7 (b) and 7 (c), respectively.

\section{Experimental setup and data collection}

\subsection{OCT specimens}

The mechanical tests for the OCT specimens were carried out using a $100 \mathrm{kN}$ Instron testing machine equipped with $10 \mathrm{kN}$ and $100 \mathrm{kN}$ load cells to measure the initiation and propagation loads for growing the crack in the warp and weft directions, respectively. The crosshead displacement and load histories were recorded by using a data acquisition system. The tests were carried out with crosshead displacement rate of $1 \mathrm{~mm} / \mathrm{min}$. Two different lay-ups were used, namely unidirectional $\left(0_{2}\right)_{2 \mathrm{~s}}$ and cross-ply $(0,90)_{2 \mathrm{~s}}$ for determination of the toughness in the warp and weft directions, respectively. The nominal thickness for both unidirectional and cross-ply panels was $3.6 \mathrm{~mm}$. Prior to testing, all specimens were prepared using a two stage painting procedure. This procedure is required by the digital speckle photogrammetry system in order to compute the strain field histories during the test. Firstly, one of the faces of the specimens was painted white in order to provide a white background for the black speckles introduced in the second stage. In the second stage, fine black speckles were uniformly sprayed into the white painted face of the specimen. After spraying the black speckles on the specimens, a $20 \mathrm{~mm}$ scale ruler equally divided into increments of $1 \mathrm{~mm}$ was drawn parallel and ahead of the initial crack. A set of two cameras orientated at $12.5^{\circ}$ with respect to the direction normal to the face of the specimen was used to record the displacement and strain field histories during the test. Additionally, an extra CCTV camera connected to a TV set was placed normal to the specimen to monitor the crack growth. By using this extra camera together with a crack event marker, it was possible to determine the load and displacements associated with a specific crack length. The experimental setup for measuring the intralaminar fracture toughness using OCT specimens is shown in Fig. 8.

\subsection{DEN specimens}

The same equipment described previously was used to measure the displacements and load histories during the test. $10 \mathrm{kN}$ and $100 \mathrm{kN}$ load cells were used to measure the load histories in the weft and warp directions, respectively. The specimens were loaded at a displacement rate of $0.5 \mathrm{~mm} / \mathrm{min}$. The specimen preparation followed the same steps as that for the OCT 


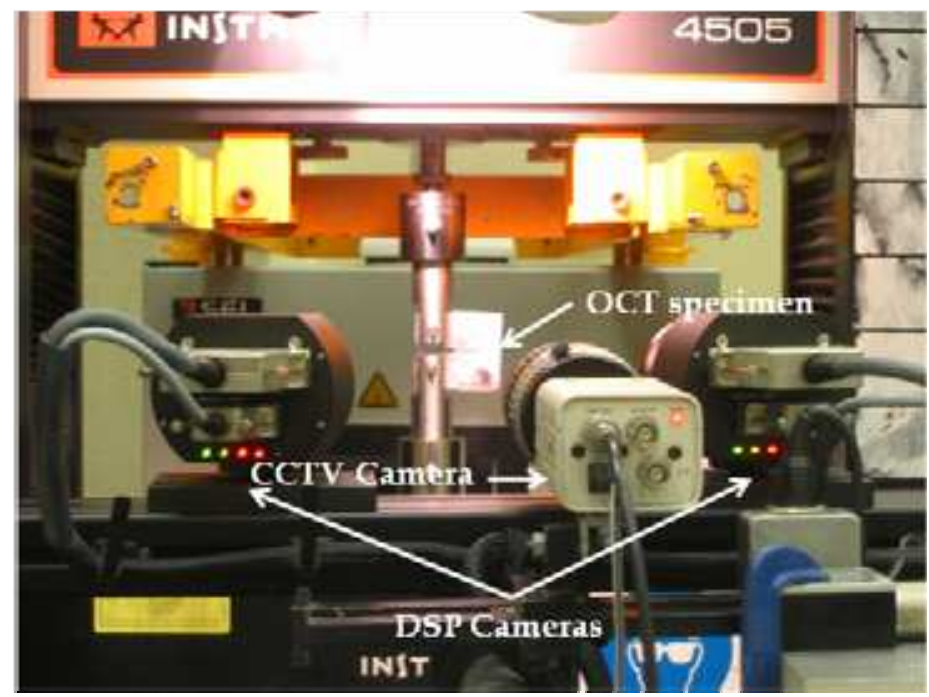

Fig. 8. Experimental setup for OCT specimens

specimens. The digital speckle photogrammetry system was used to identify the position of the crack tip. Prior to testing the specimens were end tabbed and fixed in the testing machine by means of the jaws as shown in Fig. 9.

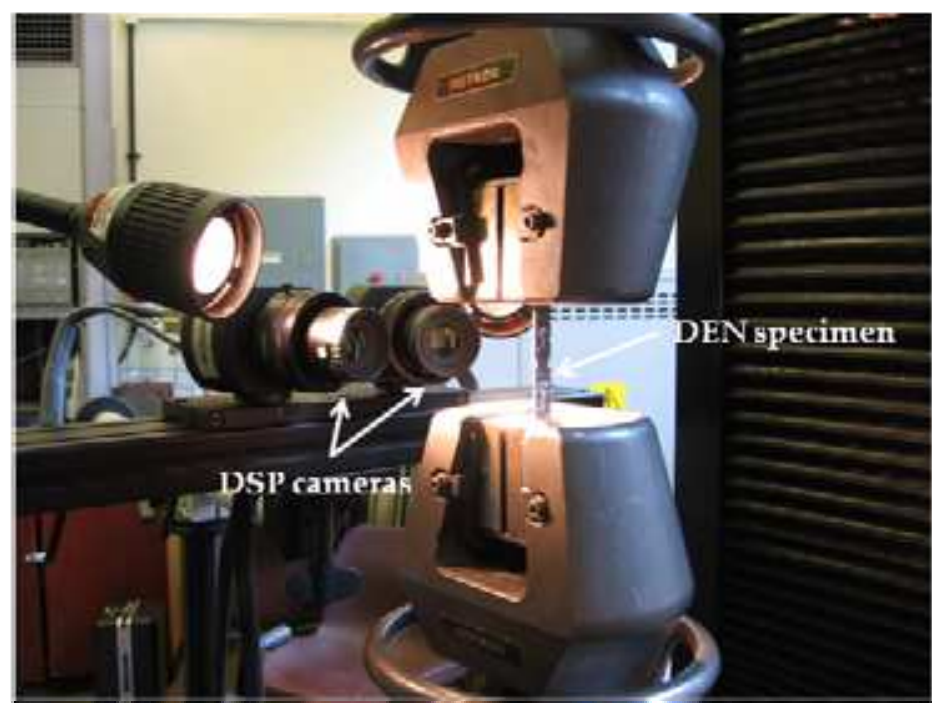

Fig. 9. Experimental setup for DEN specimens

\subsection{Four point bending specimens}

Due to the unstable nature of the crack grow th in this specimen geometry, only the initiation value could be experimentally obtained and hence no use was made of digital speckle 
photogrammetry. A $10 \mathrm{kN}$ loading cell was used and the tests were carried out at $0.5 \mathrm{~mm} / \mathrm{min}$. Crosshead displacements and load histories were recorded during the test using a data acquisition system. The specimens were loaded by means of the four point loading jig according to Fig. 10. A rubber film was placed between the specimens and the loading jig in order to prevent lateral sliding.

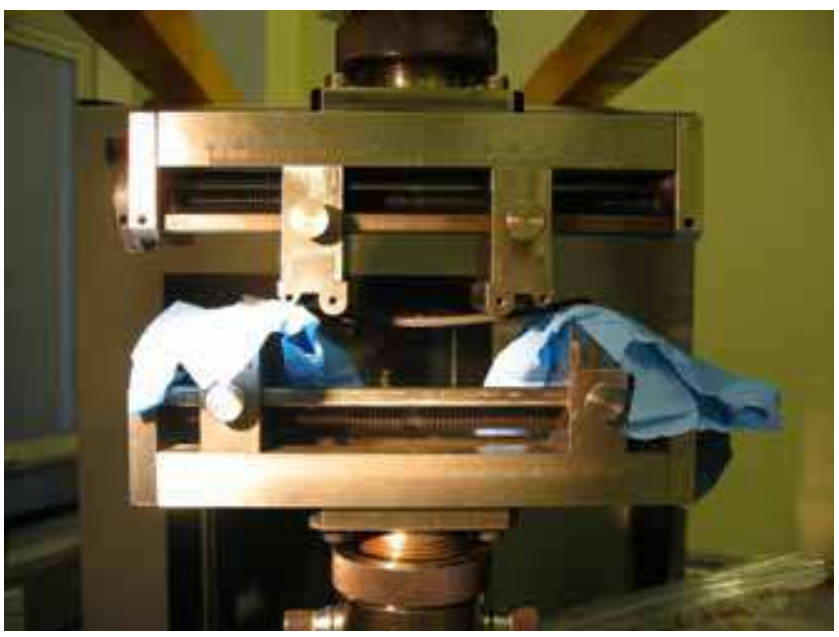

Fig. 10. Experimental setup for 4PBT specimens

\section{Experimental results}

Five unidirectional OCT specimens were tested and a typical load-displacement curve is shown in Fig. 11.

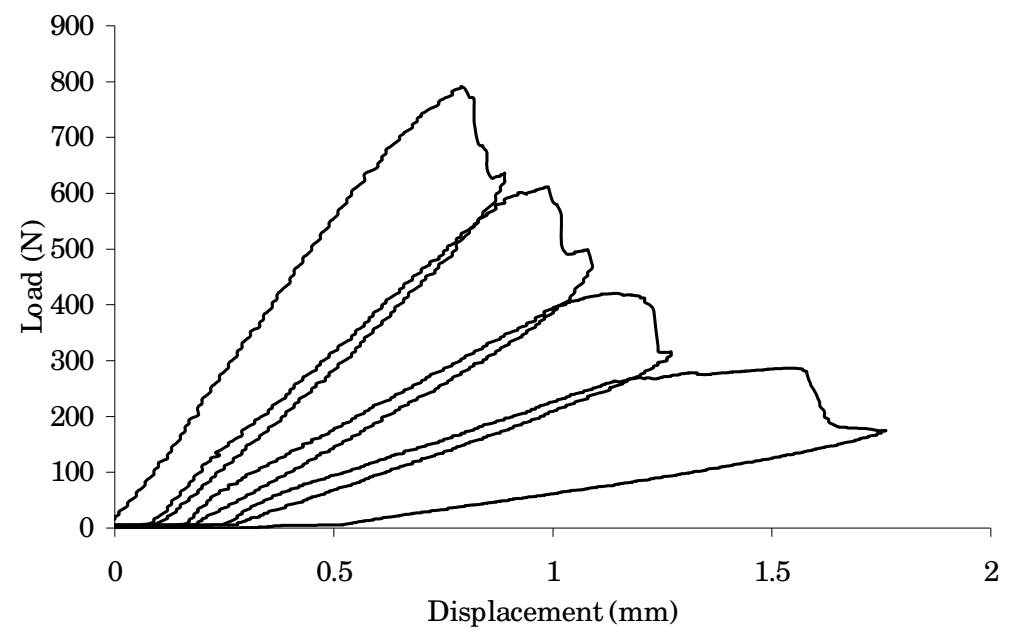

Fig. 11. Load-displacement curves for unidirectional specimens 
All specimens were immediately unloaded for each crack increment and up to four cycles could be obtained before the crack reached the edge of the specimen.

The load displacement curve exhibits a stick-slipping behaviour which is attributed to the fracture of the transverse glass fibres normal to the crack growth direction. The spacing between two subsequent peak loads is fairly consistent from specimen to specimen and the interval is associated with the spacing between two consecutive normal glass fibre yarns. As a result, the toughness in the weft direction will be given by the sum of the toughness associated with matrix cracking plus the toughness associated with glass fibre fracture. The permanent displacements during the unloading stage are mainly due to micro-cracking damage (such as fibre/ matrix debonding) and interaction between fragments of fractured glass fibres which results in partial crack closure. As an initial assessment, the toughness values were determined using the compliance method (Slepetz \& Carlson, 1975). Additionally, numerical simulations were carried out in order to evaluate the compliance changes for different crack lengths. The crack tip position was identified by using the digital speckle photogrammetry system and a typical experimental strain contour is shown in Fig. 12. The experimental and numerical compliance variations with respect to the crack length are shown in Fig. 13.

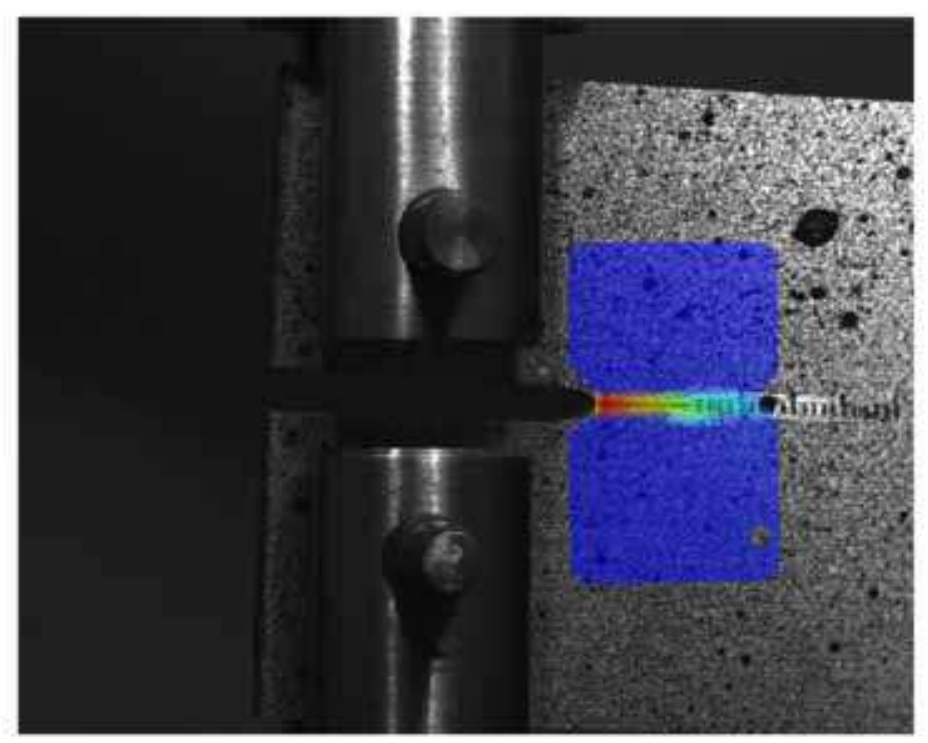

Fig. 12. Experimental strain field for the OCT specimens

Based on the correlation between numerical and experimental results a polynomial cubic relationship between compliance versus crack length was defined in the following form,

$$
C(a)=c_{1} a^{3}+c_{2} a^{2}+c_{3} a+c_{4}
$$

where the best fit coefficients were $c_{1}=3,4461.10^{-6}, c_{2}=-3,2348.10^{-4}, c_{3}=1,0249.10^{-2}$ and $c_{4}=-0.1080$, respectively. The toughness values for the unidirectional OCT specimens were computed using the following expression (Slepetz \& Carlson, 1975), 


$$
G_{I c}=\frac{P_{c}^{2}}{2 h} \frac{\partial C}{\partial a}
$$

where $P_{c}$ is the critical load associated with a given crack length and $h$ is the thickness of the specimen. The toughness values for the unidirectional specimens tested are presented in Fig. 14.

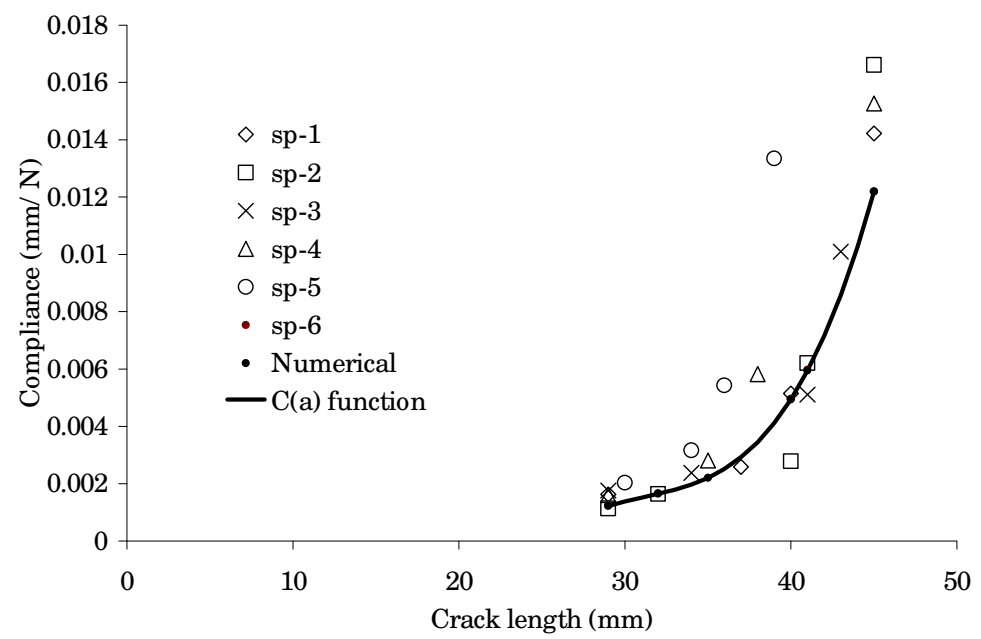

Fig. 13. Experimental compliance versus crack length for unidirectional OCT specimens

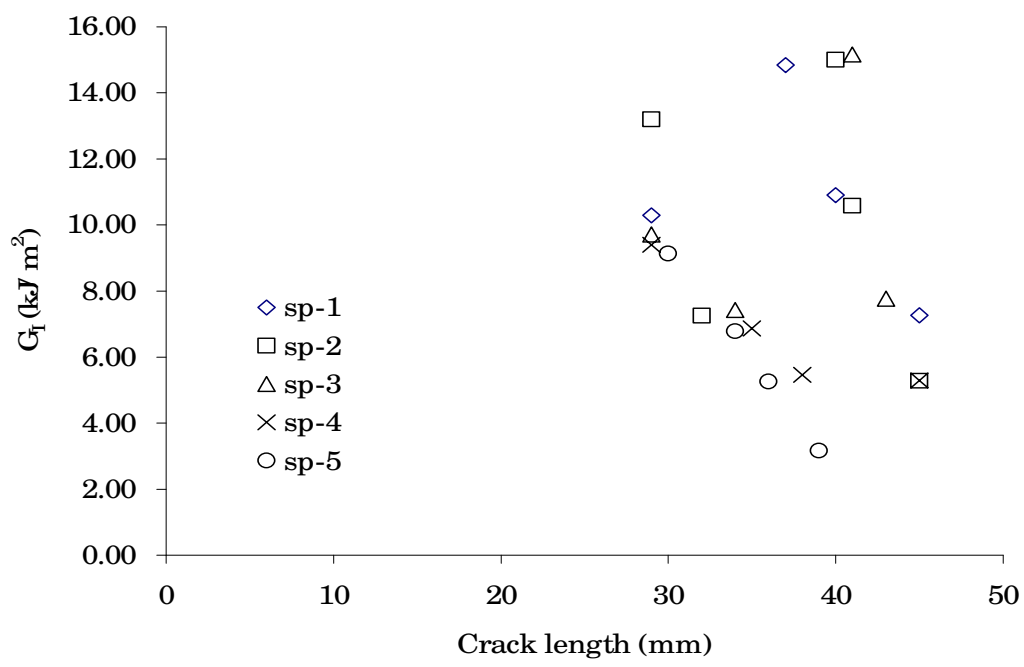

Fig. 14. Experimental toughness values for the unidirectional OCT specimens (R-Curve)

A large scatter for the toughness values was obtained, with a resultant mean value around $10 \mathrm{~kJ} \mathrm{~m}^{2}$ and standard deviation of $3.2 \mathrm{~kJ} \mathrm{~m}^{2}$. In fact this is not surprising since the fracture 
process is very complex in fabrics of this nature. The variations in the initial values may be attributed to the intra-planar heterogeneities of the constituents and location of the initial crack tip which for some specimens was within the glass fibre yarns and for others only in resin rich areas. Fibre bridging was also observed which may explain the dispersion in results for higher crack length values. Also, the crack did not propagate in a perfect straight line as it was intended, but followed a tortuous path which may have resulted in coupling between different fracture modes (mode I and mode II for instance) (See Fig. 15). Crack bifurcation mainly in the regions close to the transverse glass fibres was also observed. Moreover, the number of glass fibre yarns normal to the fracture surface varied along the crack growth line from specimen to specimen due to the non-uniform distribution arising from the manual lay-up stage. These processes either together or individually introduce extra dissipation mechanisms during the fracture process which may explain such a variation. The low toughness values may be attributed to matrix cracking only whereas the high toughness values to the glass fibre fracture. It is very difficult to distinguish and attribute a particular toughness value to each fracture mechanism involved in the fracture process and one may assume the mean value as a reasonable one for design purposes.

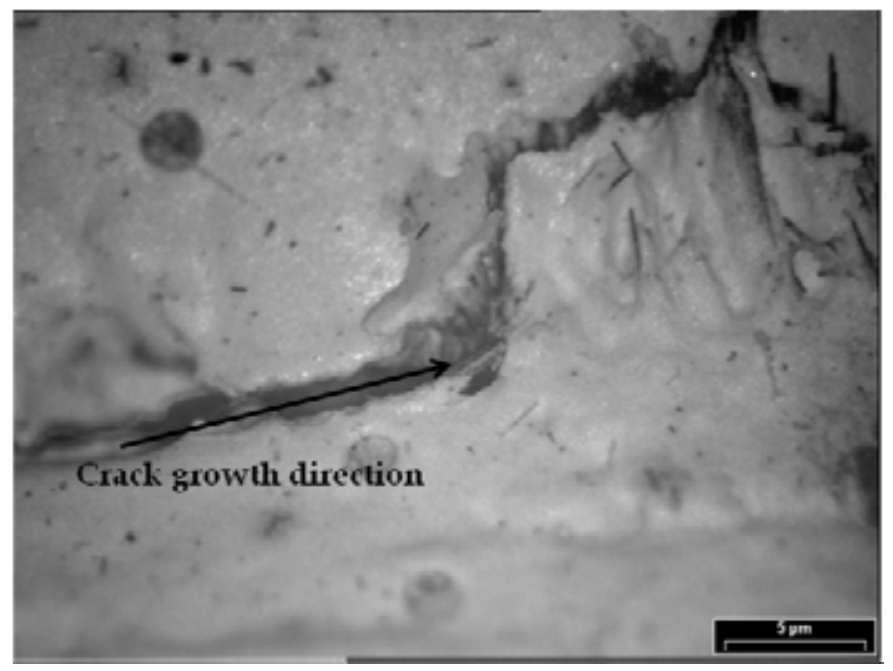

Fig. 15. Intralaminar crack growth path

For the DEN and Four-Point-Bending (4PBT) specimens only the initiation values could be experimentally obtained due to the unstable crack growth on those specimens. For the DEN specimens the applied tension stresses remote from the crack were computed by dividing the ultimate load by the cross-sectional area of the specimen. Having defined the stress, Eqs (3) and (4) were then applied to obtain the toughness values. For specimens loaded in the weft direction, failure took place within the pre-cracked region, as intended, but this was not the case for specimens loaded in the warp direction. A mean toughness value of $G_{I c}=2.50 \pm$ $0.25 \mathrm{~kJ} / \mathrm{m}^{2}$ was found for the specimens loaded in the weft direction and Fig. 16 depicts the observed failures modes in each direction for DEN specimens.

For the 4PBT specimens the intralaminar fracture toughness values were computed using Eqs. (5), (6) and (8) and a mean toughness value of $G_{I c}=2.20 \pm 0.12 \mathrm{~kJ} \mathrm{~m}^{2}$ was found. It was 
noticed that four point bending test specimens showed a lower scatter in results compared to the DEN specimens. In fact, having double pre-cracked specimens such as DEN specimens may introduce extra sources of errors and variations in the results such as asymmetrical crack tip sharpness and non-self-similar crack growth. The values obtained using the 4PBT specimens compare well with the one obtained from the DEN tests confirming the initiation toughness values in the weft direction.

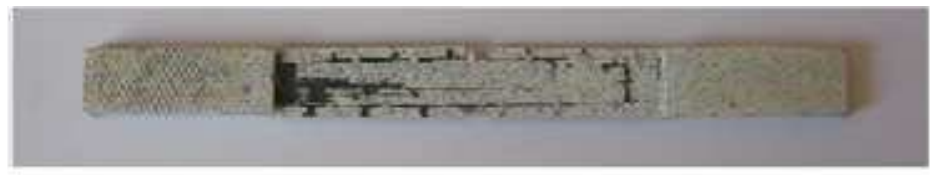

(a)

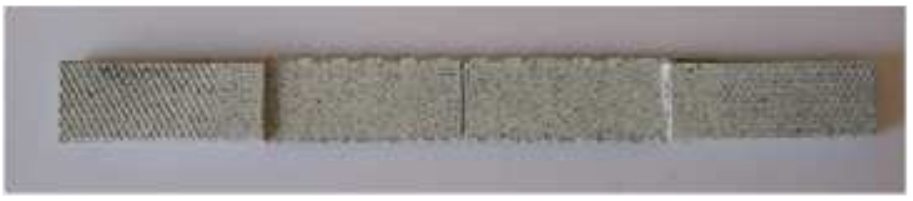

(b)

Fig. 16. Failure modes for DEN specimens: (a) Warp direction, (b) Weft direction

\section{Finite element modelling}

\subsection{FE model setup for the OCT specimen}

The OCT specimen was modelled using 8-node quadratic plane stress elements available in ABAQUS/ Standard. The dimensions for the virtual unidirectional coupon were $51 \times 30 \times 3.6$ $\mathrm{mm}^{3}$. Due to the symmetry of the problem, only one half of the specimen was modelled and a finer mesh was assigned to the region around the crack tip in order to obtain an accurate representation of the stress/strain fields on that region. A typical FE mesh is shown in Fig. 17.

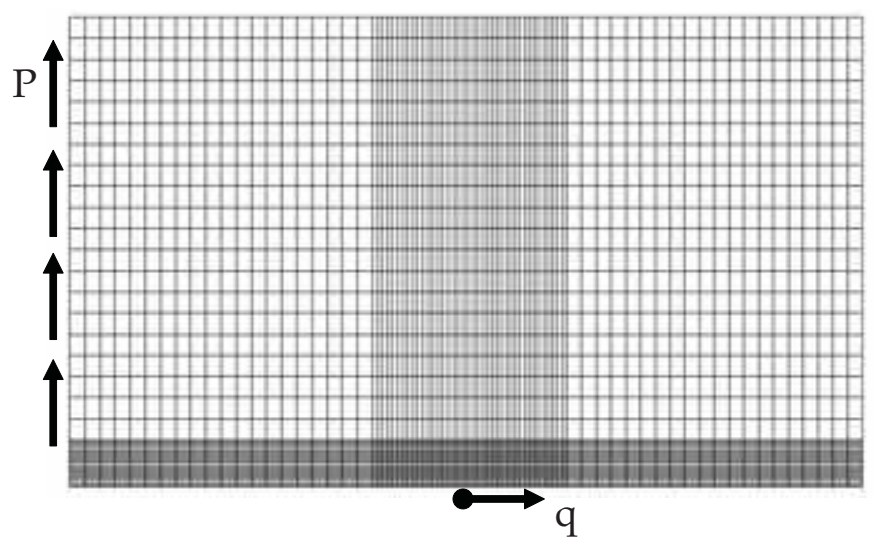

Fig. 17. FE mesh used for OCT simulations 
In order to model the contact forces between the loading pins and composite specimen the load was assumed to be uniformly distributed along the loading line of the specimens as shown in Fig. 17. The material behaviour was modelled using linear orthotropic elastic material model available in ABAQUS/ Standard with mechanical properties given in Table 1. The virtual crack extension direction was assumed to be normal to the loading direction and defined by a vector $q=(1,0,0)$. The simulations were performed for crack lengths of $28 \mathrm{~mm}, 37 \mathrm{~mm}$ and $40 \mathrm{~mm}$ and the Jintegral values were evaluated on ten different integral contours for each crack length. Mean Jintegral values of $9.91766 \pm 0.015 \mathrm{ke}^{\mathrm{m}} \mathrm{m}^{2}, 10.8025 \pm$ $0.012 \mathrm{~kJ} \mathrm{~m}^{2}$ and $11.4708 \pm 0.014 \mathrm{~kJ}^{2} \mathrm{~m}^{2}$ were obtained for the crack lengths of $28 \mathrm{~mm}, 37 \mathrm{~mm}$ and $40 \mathrm{~mm}$, respectively. The numerical results were very consistent confirming the path independency of the Jintegral method and they correlate reasonably well with the average experimental toughness obtained using the compliance method. This correlation confirms that the values derived from the compliance method are representative of the toughness behaviour for the material under investigation. An extra evaluation was carried out using the expression from the ASTM E399-90 standard to verify the validity of the expressions for orthotropic materials. A comparison between ASTM, compliance, Jintegral and results obtained using the proposed method described in section 3 are shown in Fig. 18. Fig. 19 shows a comparison between the original ASTM and modified correction function obtained using Eq. (14).

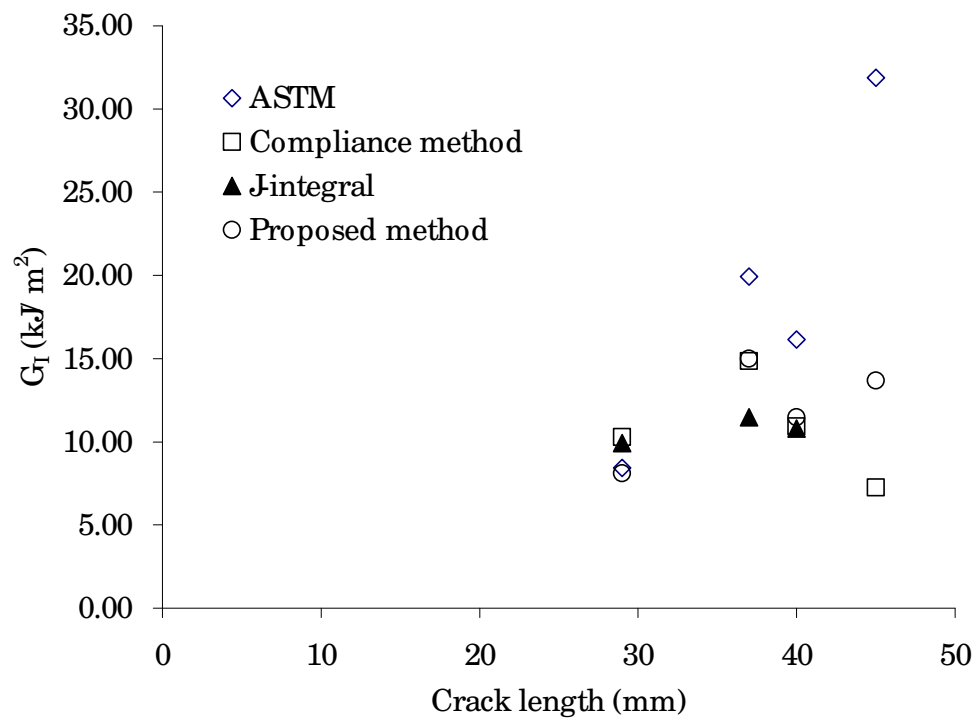

Fig. 18. Comparison between different methods for computing $G_{I c}$ using OCT specimens

It can be seen from Fig. 18 that there is a reasonably good agreement between the ASTM and compliance method for the initiation values of $G_{I c}$ however the propagation values are over predicted by the ASTM standard compared to the numerical values. On the other hand, despite these variations, the experimental values obtained using the compliance method varies consistently around the average numerical values. 


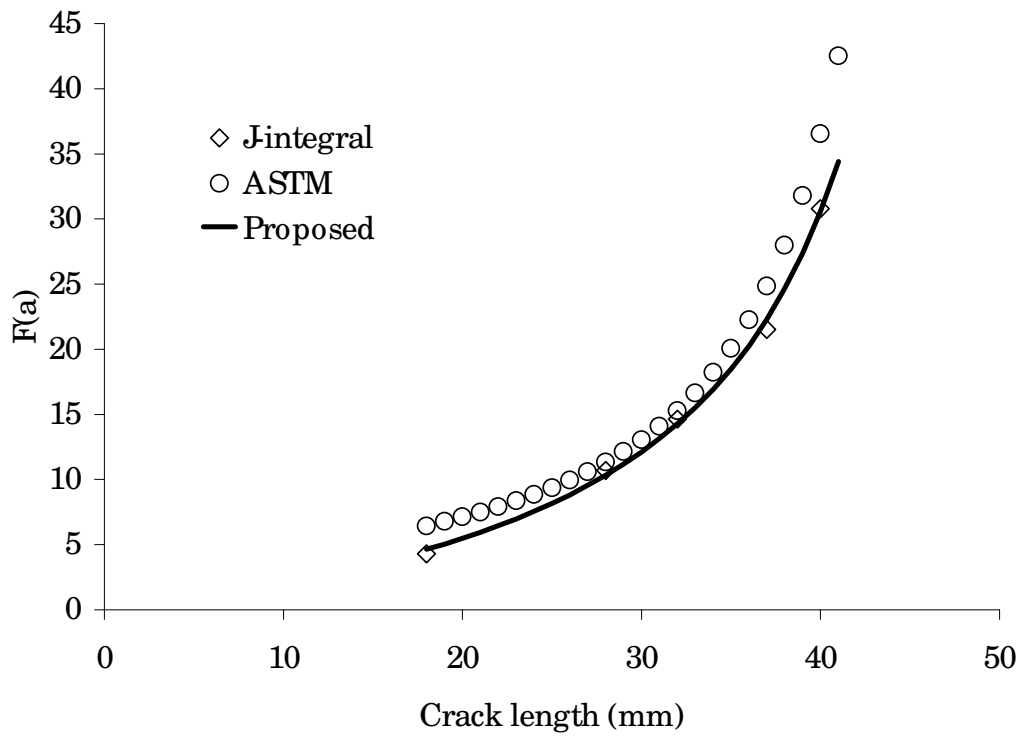

Fig. 19. Comparison between correction functions for determination of $K_{I c}$

\subsection{FE model setup for the DEN specimen}

The DEN specimen was modelled using 8-node quadratic plane stress elements. Due to the symmetry of the problem, only one quarter of the specimen was modelled. A finer mesh was assigned to the region around the crack tip in order to obtain an accurate representation of the stress/ strain fields on that region. The ultimate load was uniformly distributed along the top edge of the virtual specimen. A close look at the FE mesh around the crack tip is shown in Fig. 20.

The Jintegral was evaluated on ten different integration contours with mean values of $2.2 \pm 0.011 \mathrm{~kJ}^{J} \mathrm{~m}^{2}$ and $170 \pm 0.013 \mathrm{~kJ} \mathrm{~m}^{2}$ for the specimens loaded in the weft and warp directions, respectively. The numerical results agree reasonably well with experimental ones which confirm the initiation values obtained using DEN specimens. It also confirms the values obtained using $4 \mathrm{PBT}$ specimens which were around $2.2 \mathrm{~kJ} / \mathrm{m}^{2}$. For the virtual DEN specimens loaded in the warp direction a value around $170 \mathrm{~kJ} \mathrm{~m}^{2}$ was numerically obtained which also agree very well with $165 \mathrm{~kJ} \mathrm{~m}^{2}$ obtained using the compliance method.

\subsection{FE model setup for the 4PBT specimen}

A three-dimensional orthotropic model was generated using ABAQUS/ CAE to calculate the toughness values in the weft direction based on the Jintegral method for the four point bending specimens. The specimen had a $\left(90^{\circ}\right)_{10}$ lay-up with dimensions given in Fig.3. The virtual specimen was discretised using 20 -node quadratic brick elements. A finer mesh was assigned to the crack tip region in order to better represent the stress/ strain field on that region. The crack front line and the virtual crack extension vector were defined through-thethickness direction by taking the free sides of the elements at the crack tip and one half of the total load was uniformly distributed along the contact line between specimen and upper testing jig. Due to the symmetry of the problem only one fourth of the specimen was 


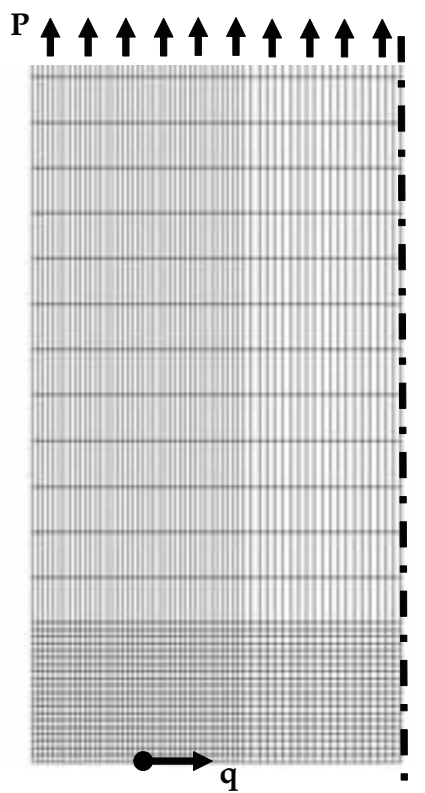

Fig. 20. FE mesh for the DEN specimens

modelled and a typical FE mesh is shown in Fig. 21. A mean value of $25 \pm 0.01 \mathrm{ke}^{\mathrm{m}} \mathrm{m}^{2}$ was obtained for the Jintegral and this result agrees well with the experimental values and numerical results obtained for DEN specimens. Unfortunately due to the unstable nature of crack growth it was not possible to derive a specific correction function for this specimen geometry and the validity of Eq. (6) remains questionable.

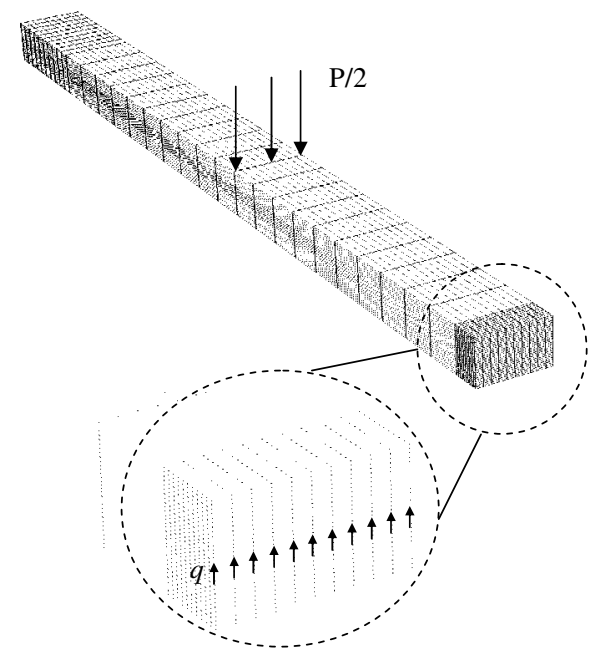

Fig. 21. FE mesh for the four point bending specimen (4PBT) 


\section{Concluding remarks}

This chapter presented a detailed numerical and experimental study on the intralaminar fracture behaviour of hybrid plain weave laminates under mode I loading using different specimen geometries and data reduction schemes. Based on the numerical and experimental results the following conclusions were obtained:

- The fracture behaviour of hybrid plain weave laminates is far more complex than conventional UD laminates due to interactions between two different fibrous constituents and matrix which may result in a local coupling between different failure modes (mode I/ mode II) during the fracture process;

- The class of material investigated exhibited much higher intralaminar toughness values compared to conventional UD laminates making them good candidates for designing damage resistant/ tolerant composite aerostructures;

- A lower scatter in the toughness values was obtained using 4PBT specimens;

- Initiation and propagation toughness values around $2 \mathrm{~kJ} \mathrm{~m}^{2}$ and $10 \mathrm{~kJ} / \mathrm{m}^{2}$, respectively, were obtained in the weft direction;

- Initiation and propagation toughness values around $100 \mathrm{~kJ} / \mathrm{m}^{2}$ and $165 \mathrm{~kJ}^{2}$, respectively, were obtained in the warp direction;

- The application of the ASTM E399-90 is questionable for composites in general and it can overestimate the toughness values by factors higher than three if used in its original form;

A methodology to derive a new correction function accounting for geometry and orthotropic effects was presented and discussed in this chapter. The methodology can handle different geometries giving better correlation with experimental results compared with standard methods.

\section{References}

ABAQUS 6.5-1. (2005). Theoretical manual.

Brown, W.F., Jr. and Strawley, J.E. (1967). Plane strain crack toughness testing of high strength metallic materials, ASTM STP 410, American Society for Testing and Materials.

Cowley D.K., Beaumont P.W.R. (1997). The interlaminar and intralaminar fracture toughness of carbon-fibre/ polymer composites: The effect of temperature. Composite Science and Technology, Vol. 57, pp. 1433-1444, ISSN 0266-3538.

Donadon M.V., Hodgkinson J.M., Falzon B.G., Iannucci L. (2004a). The reliability of the resin infusion under flexible tooling process for manufacturing composites aerostructures. Proceedings of the 13th Sicomp, Sweden, September, 2004.

Donadon M.V., Hodgkinson J.M., Falzon B.G., Iannucci L., (2004b). The impact behaviour of composites manufactured using resin infusion: Mechanical and physical properties assessment, Internal report, Dept. of Aeronautics, Imperial College London.

Donadon M.V, Hodgkinson J.M., Falzon B.G., Iannucci L. (2004c). Impact damage in composite structures manufactured using resin infusion under flexible tooling (RIFT) process. Proceedings of the ECCM-11, Greece, 2004. 
Donadon M.V, Hodgkinson J.M., Falzon B.G., Iannucci L. (2007). Intralaminar toughness characterisation of unbalanced hybrid plain weave laminates. Composites Part A: Applied Science and Manufacturing, Vol. 38, No. 6, pp. 1597-1611, ISSN: 1359835X.

Donadon M.V, Almeida S. F. M., Arbelo M. A., de Faria A. R. (2009). A three-dimensional ply failure model for composite structures. International eburnal of Aerospace Engineering, Vol. 2009, pp. 1-22, ISSN: 1687-5966.

Iannucci L., Willows M.L. (2006). An energy based damage mechanics approach to modelling impact onto woven composite materials-Part I: Numerical models. Composites Part A: Applied Science and Manufacturing, Vol. 37, No. 11, pp. 2041-2056, ISSN: 1359-835X.

Jose S., Kumar R.R., Jana M.K., Rao G.V. (2001). Intralaminar fracture toughness of a crossply laminate and its constituent sub-laminates. Composite Science and Technology, Vol. 61, pp. 1115-1122, ISSN: 0266-3538.

Konstantinos G. D, Kostopoulos V., Steen M. (2005). Intrinsic paramaters in the fracture of carbon/ carbon composites. Composite Science and Technology, Vol. 65, pp. 883-897, ISSN: 0266-3538.

Kostopoulos V, Markopoulos Y.P., Pappas Y.Z., Peteves S.D. (1998). Fracture energy measurements of 2-D Carbon/ Carbon composites. eburnal of European Ceramic Society Vol. 18, pp. 69-79, ISSN: 0955-2219.

Lin G. Y., Shetty D. (2003). Transformation zones, crack shielding, and crack-growth resistance of Ce-TZP/ alumina composite in mode $I I$ and combined mode $I I$ and mode I loading. Engineering Fracture Mechanics, Vol. 70, pp. 2569-2585, ISSN: 00137944.

Lin, S. T., Feng Z., Rowlands R.E. (1997). Thermoelastic determination of stress intensity factors in orthotropic composites using Jintegral. Engineering Fracture Mechanics, Vol. 56, No. 4, pp. 579-592, ISSN: 0013-7944.

Pinho S.T, Robinson P., Iannucci L. (2004). Intralaminar fracture toughness of laminated composites: manufacture of specimens with sound pre-cracks. Internal Report, Dept. of Aeronautics, Imperial College London, 2004.

Pinho S.T, Robinson P., Iannucci L. (2006a). Fracture toughness of the tensile and compressive fibre failure modes in laminated composites. Composite Science and Technology , Vol. 66, No. 13, pp. 2069-2079, ISSN: 0266-3538.

Pinho S.T, Robinson P., Iannucci L. (2006b). Physically-based failure models and criteria for laminated fibre-reinforced composites with emphasis on fibre kinking: Part I: Development. Composites Part A: Applied Science and Manufacturing, Vol. 37, No. 1, pp.63-73, ISSN: $1359-835 \mathrm{X}$.

Paris, P.C, Sih C. G. (1960). Stress analysis of cracks, fracture toughness and applications, STP-381, ASTM 1960; pp. 30-83.

Rooke D. P., Cartwright D.J. (1976). Compendium of stress intensity factors. London HMSO 1976.

Martin R. H., Elms T., Bowron S. (1998). Characterisation of mode II delamination using the 4ENF. Proceedings of the 4th European Conference on Composites: Testing and Standardisation, Lisbon Portugal, 31st August-2 ${ }^{\text {nd }}$ September 1998. 
Standard test method for plane strain fracture toughness of metallic materials, ASTM E39990, Annual book of ASTM standards 03.01 1993; pp. 407-528

Slepetz J.M., Carlson. (1975). Fracture of composite compact tension specimens, ASTM STP 593, American Society for Testing and Materials 1975. 


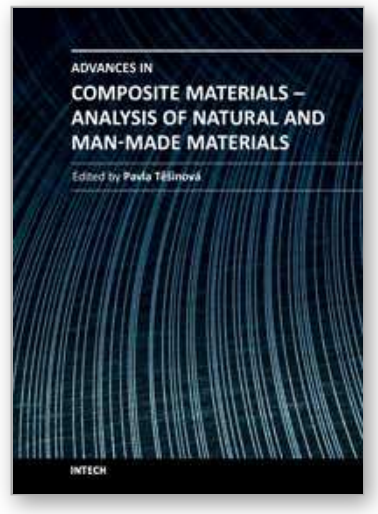

\author{
Advances in Composite Materials - Analysis of Natural and Man- \\ Made Materials \\ Edited by Dr. Pavla Tesinova
}

ISBN 978-953-307-449-8

Hard cover, 572 pages

Publisher InTech

Published online 09, September, 2011

Published in print edition September, 2011

Composites are made up of constituent materials with high engineering potential. This potential is wide as wide is the variation of materials and structure constructions when new updates are invented every day.

Technological advances in composite field are included in the equipment surrounding us daily; our lives are becoming safer, hand in hand with economical and ecological advantages. This book collects original studies concerning composite materials, their properties and testing from various points of view. Chapters are divided into groups according to their main aim. Material properties are described in innovative way either for standard components as glass, epoxy, carbon, etc. or biomaterials and natural sources materials as ramie, bone, wood, etc. Manufacturing processes are represented by moulding methods; lamination process includes monitoring during process. Innovative testing procedures are described in electrochemistry, pulse velocity, fracture toughness in macro-micro mechanical behaviour and more.

\title{
How to reference
}

In order to correctly reference this scholarly work, feel free to copy and paste the following:

Mauricio V. Donadon and Sérgio Frascino Muller de Almeida (2011). Intralaminar Fracture Toughness Characterization of Composite Laminates, Advances in Composite Materials - Analysis of Natural and ManMade Materials, Dr. Pavla Tesinova (Ed.), ISBN: 978-953-307-449-8, InTech, Available from:

http://www.intechopen.com/books/advances-in-composite-materials-analysis-of-natural-and-man-madematerials/intralaminar-fracture-toughness-characterization-of-composite-laminates

\section{INTECH}

open science | open minds

\section{InTech Europe}

University Campus STeP Ri

Slavka Krautzeka 83/A

51000 Rijeka, Croatia

Phone: +385 (51) 770447

Fax: +385 (51) 686166

www.intechopen.com

\section{InTech China}

Unit 405, Office Block, Hotel Equatorial Shanghai

No.65, Yan An Road (West), Shanghai, 200040, China

中国上海市延安西路65号上海国际贵都大饭店办公楼 405 单元

Phone: +86-21-62489820

Fax: $+86-21-62489821$ 
(C) 2011 The Author(s). Licensee IntechOpen. This chapter is distributed under the terms of the Creative Commons Attribution-NonCommercialShareAlike-3.0 License, which permits use, distribution and reproduction for non-commercial purposes, provided the original is properly cited and derivative works building on this content are distributed under the same license. 